$\Rightarrow$ ADDICTIVE DRUGS

\section{Benzodiazepine's hook}

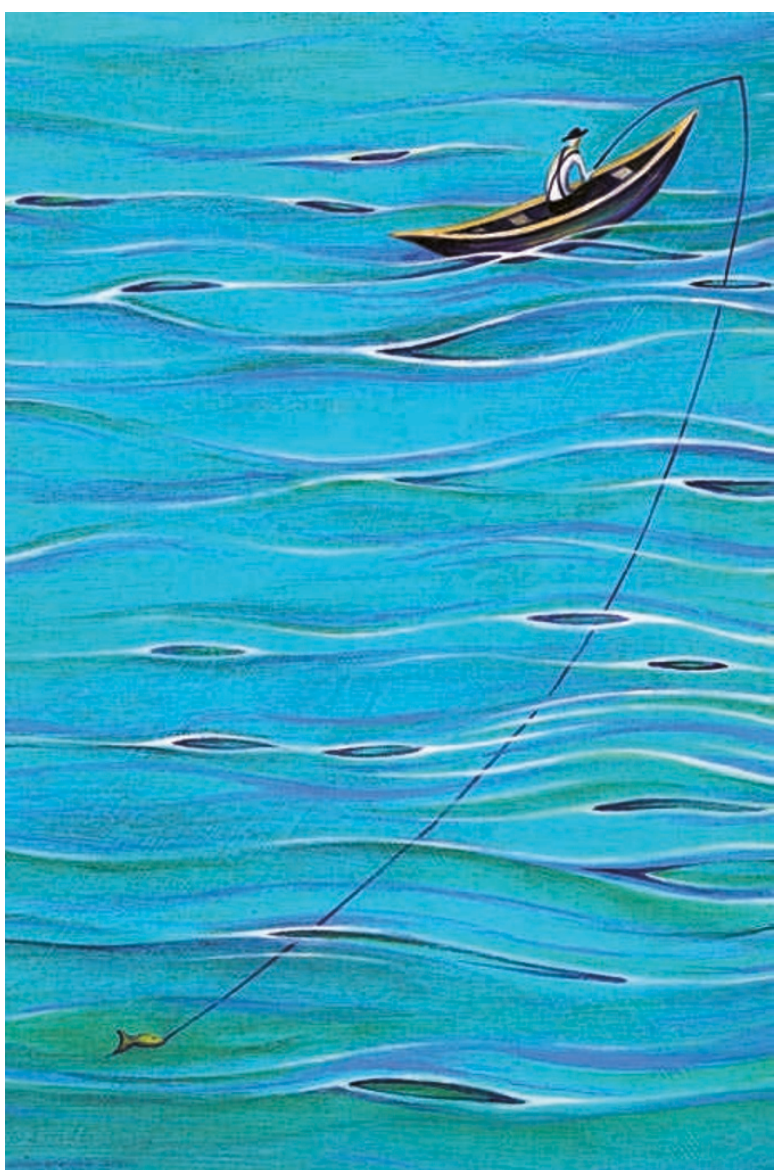

Benzodiazepines exert rapid anxiolytic effects by increasing GABA $(\gamma$-aminobutyric acid)-mediated neurotransmission. However, their use in treating anxiety disorders is limited owing to the loss of control of consumption after prolonged use. Lüscher and colleagues now show that positive modulation of $\mathrm{GABA}_{\mathrm{A}}$ receptors containing the al subunit in the ventral tegmental area (VTA) underlies the addictive nature of benzodiazepines and suggest that the design of $\alpha 1$-sparing compounds could lower the risk of addiction.

Addictive drugs increase mesolimbic dopamine levels by reducing the inhibition of dopaminergic neurons (an effect known as disinhibition), by directly depolarizing dopaminergic neurons or by inhibiting dopamine transporters. Addictive drugs also trigger long-lasting changes in the VTA, which can be measured as an increase in the AMPA ( $\alpha$-amino3-hydroxy-5-methyl-4-isoxazole propionic acid)/NMDA ( $N$-methyl$\mathrm{D}$-aspartate) ratio and a change in the gradient of the current-voltage curve of evoked excitatory postsynaptic currents (EPSCs).

The authors showed that benzodiazepines induced such changes in the mouse VTA circuitry 24 hours after injection, and went on to examine whether these effects were dependent on the activation of particular $\mathrm{GABA}_{\mathrm{A}}$ receptor isoforms. Interestingly, the benzodiazepineinduced adaptive plasticity was lost in mice with a mutation in the al subunit of $\mathrm{GABA}_{\mathrm{A}}$ receptors (H101R) that disrupts binding of the drug. Similarly, a subtype-selective
$\mathrm{GABA}_{\mathrm{A}}$ receptor modulator that acts as a partial agonist at $\alpha 2, \alpha 3$ and $\alpha 5$ subtypes but as an antagonist at the al subtype and has anxiolytic properties did not induce adaptive plasticity, indicating that this effect is dependent on al subunit-containing receptors in the VTA.

Immunohistochemical staining revealed that the VTA is enriched in GABAergic neurons containing the a1-subunit isoform of the $\mathrm{GABA}_{\mathrm{A}}$ receptor. Moreover, in vivo electrophysiological recordings showed that benzodiazepineinduced disinhibition of dopamine neurons in the VTA was abolished in H101R mice, but not in mice in which other a-subunit isoforms were mutated. Finally, the authors showed that H101R mice do not develop a preference for a drinking solution containing benzodiazepines, yet still develop a strong preference for a sucrose solution over water, indicating that their general reward reinforcement pathway is intact.

These findings not only show that benzodiazepines increase dopamine levels through disinhibition but also, by implicating $\mathrm{GABA}_{\mathrm{A}}$ receptors that contain the $\alpha 1$ subunit in addiction liability, point towards a new strategy to design improved anxiolytics.

Monica Hoyos Flight

ORIGINAL RESEARCH PAPER Tan, K. R.

et al. Neural bases for addictive properties of benzodiazepines. Nature 463, 769-774 (2010) 